\title{
Recent trends in robot-assisted therapy environments to improve real-life functional performance after stroke Michelle J Johnson*1,2,3,4
}

\author{
Address: ${ }^{1}$ Medical College of Wisconsin, Dept. of Physical Medicine \& Rehabilitation, 9200 W. Wisconsin Ave, Milwaukee, WI 53226, USA, \\ ${ }^{2}$ Marquette University, Dept. of Biomedical Engineering, Olin Engineering Center, Milwaukee, WI USA, ${ }^{3}$ Clement J. Zablocki VA, Dept. of Physical \\ Medicine \& Rehabilitation, Milwaukee, WI, USA and ${ }^{4}$ The Rehabilitation Robotics Research and Design Lab, Clement J. Zablocki VA, 5000 \\ National Ave, Milwaukee, WI, USA \\ Email: Michelle J Johnson* - mjjohnso@mcw.edu \\ * Corresponding author
}

Published: 18 December 2006

Journal of NeuroEngineering and Rehabilitation 2006, 3:29 doi:10.1186/1743-0003-3-29

This article is available from: http://www.jneuroengrehab.com/content/3/I/29

(C) 2006 Johnson; licensee BioMed Central Ltd.

This is an Open Access article distributed under the terms of the Creative Commons Attribution License (http://creativecommons.org/licenses/by/2.0), which permits unrestricted use, distribution, and reproduction in any medium, provided the original work is properly cited.
Received: 28 November 2006

Accepted: 18 December 2006

\begin{abstract}
Upper and lower limb robotic tools for neuro-rehabilitation are effective in reducing motor impairment but they are limited in their ability to improve real world function. There is a need to improve functional outcomes after robot-assisted therapy. Improvements in the effectiveness of these environments may be achieved by incorporating into their design and control strategies important elements key to inducing motor learning and cerebral plasticity such as mass-practice, feedback, task-engagement, and complex problem solving.

This special issue presents nine articles. Novel strategies covered in this issue encourage more natural movements through the use of virtual reality and real objects and faster motor learning through the use of error feedback to guide acquisition of natural movements that are salient to real activities. In addition, several articles describe novel systems and techniques that use of custom and commercial games combined with new low-cost robot systems and a humanoid robot to embody the " supervisory presence" of the therapy as possible solutions to exercise compliance in undersupervised environments such as the home.
\end{abstract}

\section{Background}

Stroke is the leading cost of disability in the USA and rehabilitation is estimated to cost $\$ 60$ billion annually for the 5.4 million living with disability. Neurological impairment after stroke frequently leads to hemiparesis or partial paralysis of one side of the body. This hemiparesis can profoundly impair functional performance of activities of daily living (ADLs) such as walking, running, and eating [1]. For example, at 6 months post-stroke $50 \%$ of survivors at least 65 years old had some hemiparesis, $30 \%$ were unable to walk, and $26 \%$ were dependent in activities of daily living (ADLs).
Increasingly, robot-assisted therapy devices are used in stroke rehabilitation. Robotic tools provide opportunities to study functional adaptation after a stroke and can provide objective measurements of the time-course of changes in motor control of the affected limbs. Robotassisted therapy permits semi-autonomous practice of therapeutic tasks [2-14].

Early examples of upper limb robots such as the MITMANUS therapy robots [5] were designed to permit stroke survivors to practice two-dimensional (2-D) point-topoint movements. Other examples such as the Gentle/s [6] and MIME [7] therapy robots permit stroke survivors 
to practice three-dimensional (3D) point-to-point reaching movements occurring in a haptic virtual environment or in the real world. Typically, to practice these movements, the stroke survivor's impaired arm is supported against gravity while he/she is asked to use the impaired hand to hold the handle of the robot and move it or permit the impaired arm to be moved through reaching exercises. The length of interventions varies, but typically consists of exposure to the robot for three to five sessions per week for 4 to 8 weeks.

Early examples of robotic lower limb robots are the GT I servo-controlled gait trainer developed and used for training in the 1990s in Germany $[8,9]$ and the Lokomat manufactured by Hocoma AG (Switzerland) [10,11]. Typically, these systems simulate the phases of gait and modify key gait parameters such as stride length and walking speed. Often these systems are used in the rehabilitation of non-ambulatory patients such as those with SCI and partially ambulatory patients such as those with stroke and as such they often support some percentage of a patient's body-weight. Training often consists of repetitive stepping on a treadmill training three to five days per week for 4 to 8 weeks.

Preliminary studies using these upper and lower limb robotic tools demonstrate their effectiveness and their limitations. The extent of motor impairment reduction seen after upper limb robot-assisted therapy environments has been shown to be dependent on lesion size and location, and the treatment has been shown to be targetarea specific, e.g., training tasks emphasizing the shoulder will improve the shoulder but not the hand. In general, these upper arm systems have mixed impact on upper limb real-life function. They can reduce motor impairment after stroke, but still have mixed impact on functioning in real life use of the upper arm [2-4]. New upper arm robotic devices including exoskeletons are being proposed to examine new training strategies that focus on using more functional training environments along with virtual environments to improve carryover and reduce gravity discoordination [12-14]. More so than in the upper limb, studies show that lower limb robot-assisted therapy environments have had more success with fewer challenges to their overall effectiveness. Results do indicate that the repetitive step training, which is by nature very task-specific and relevant to real walking, does improve reduce motor impairment and functional limitations in some patients $[9,11,15]$. Although not all patients benefit and there are concerns about EMG activation patterns being different from those observed during natural walking, the training seems to improve gait parameters such as gait speed and endurance.
The mixed results from robot therapy environments, especially upper limb ones, suggest that there is still a need to optimize these treatment strategies and prove that rehabilitation robot systems are worth pursuing. If we believe this is true and that these systems have the potential to decrease long-term healthcare costs for patient, then we must clarify how best to design and use them. For answers rehabilitation engineers have begun to examine the neuroscience literature on cerebral plasticity to gain some insight into the next generation of robot therapy environments. The following briefly describes some of the relevant findings from neuro-rehabilitation and neuroscience and introduce nine articles that present new robots and new control models and feedback techniques to enrich robot-assisted therapy environments.

\section{Cerebral Plasticity}

The underlying neurological mechanisms and central nervous system recovery patterns after stroke therapy is poorly understood and this is true whether the intervention is mediated with robots or other strategies such as the Bobath method of Neuro-Development Therapy (NDT) [16]. Preliminary evidence suggests that simply moving or passively exercising the impaired limb will not lead to maximum recovery. Functional cortical reorganization and carryover of motor gains after stroke seem to be linked to therapies that involve the intense use of the impaired limb and involve the acquisition of new motor skills [19-23]. Evidence also suggests that in addition to mass-practice and use of the arm, enriched environments [17-19], highly functional and task-oriented practice environment [20-24], and highly motivating environment that increase task engagement [25-27] are important for motor re-learning and recovery after stroke. Literature supports the fact that the mechanism in mediating functional recovery seen after stroke is more than likely due to the sprouting of new synapses, the unmasking of redundant motor networks, and the re-organization of the areas around the lesion site [19].

Specifically, functional imaging studies indicate that motor recovery is characterize by the following: 1) an increase in the size of the motor and sensory areas in the lesioned hemisphere that is dedicated to the impaired limb; 2) enhance activity and recruitment in preexisting motor networks in unaffected regions and those surrounding the lesion site and in the cerebellum, and 3) a reduction the amount of activity in primary and secondary motor regions over time, especially in areas in the hemisphere ipsilateral to the lesion [24,28-32]. Similar findings have emerged from animal models of neurological plasticity [33].

Researchers have begun to respond to the neurological evidence and have begun to create robot-assisted therapy 
environments that can better capitalize on these findings and improve the likelihood of use-dependent cortical reorganization and carryover to ADL function. In this special issue, we highlight several attempts to improve the effectiveness of robot therapy environments using several extrinsic motivational techniques including feedback. Figure 1 describes the impact desired for new robotic/ mechatronic assistive systems for stroke rehabilitation and some of the methods being employed. The robotassisted environment may be modified to better engage the stroke survivor (e.g., provide extrinsic motivators), to improve its relevance to the person and the activities they do in real life (i.e., increase task-oriented nature, purpose and patient-centered), to improve feedback strategies (i.e., increase feedback of errors and results) and to improve learning strategies (i.e., employ new control strategies).

\section{Enhanced Feedback in Lower Limb Gait Rehabilitation}

The first set of two articles deals with lower limb robotics and demonstrate the use of biofeedback, virtual reality, and haptics to create more engaging gait training environments. The environments also provide opportunity for more complex and more functional gait training.

The article by Lunenburger and colleagues [34] discuss the use of biofeedback of the patient's gait performance to improve robot-assisted gait training. They demonstrate a novel strategy that uses sensors embedded in the robot environment to define and display the biofeedback values to the patient and therapists. In contrast, Schmidt and colleagues [35] focuses on the HapticWalker environment and uses virtual reality to create real-life walking environments. Their novel programming of the foot plates enable them to simulate versatile gait patterns such as walking up and down stairs.

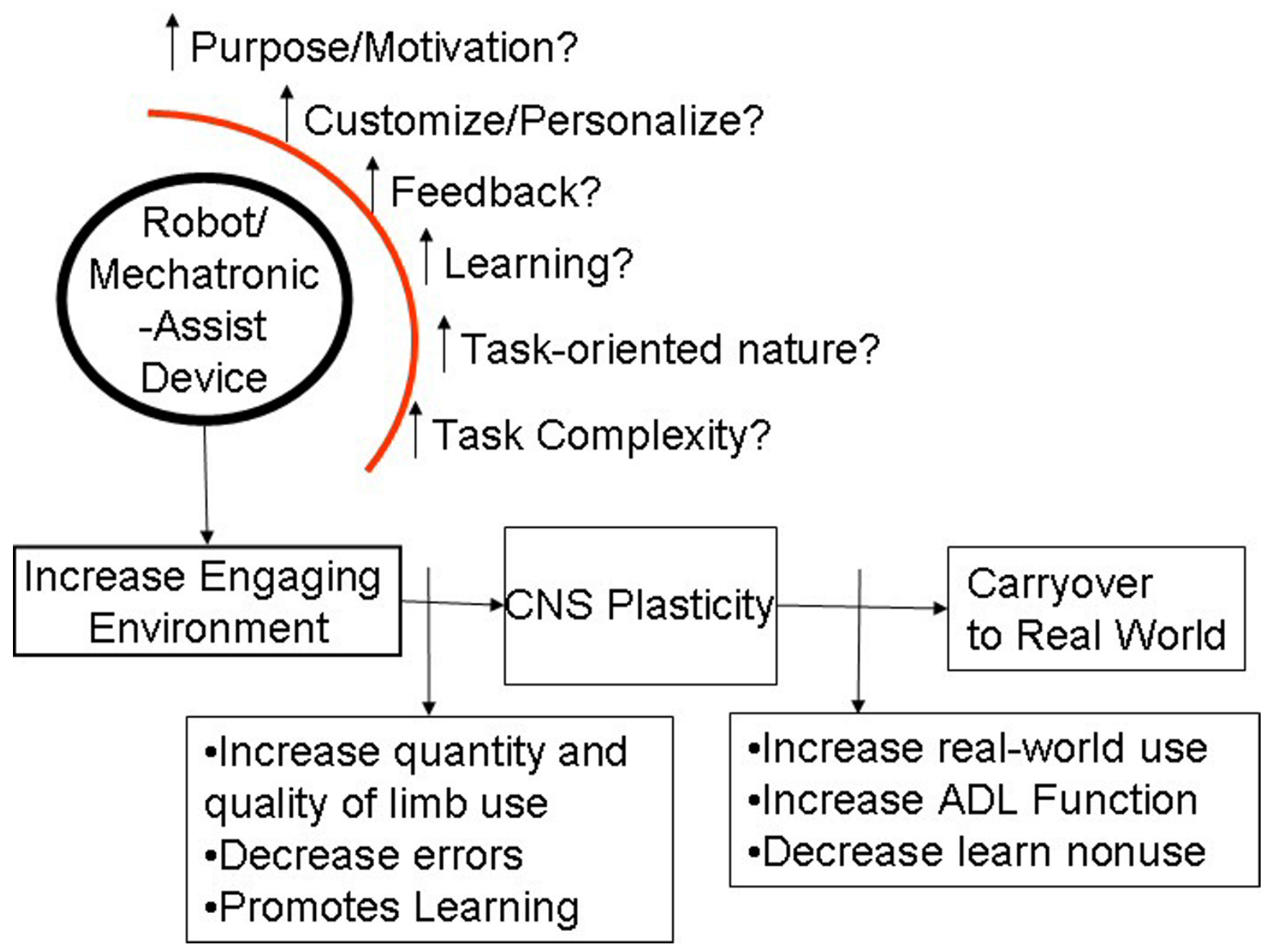

Figure I

New Ideas for Improving Robot-Assisted Therapy. In improving robot-assisted therapy to improve carryover after stroke new methods have sought to modify the environment through enhanced feedback, personalization and task relevance. 


\section{Game-Based and Social-Based Robot-Assisted Training Trends} The next set of four articles discuss new developments in upper limb robot-assisted stroke therapy from the point of view of using game- and social-oriented activities to define motivating training environments. The articles present strategies that seek to understand and improve the use of the impaired arm in daily activities in environments away from clinical supervision. In the past, robotic and computer-assisted systems such as JavaTherapy [36] and Driver's SEAT [37], designed for clinical and home rehabilitations, have used entertainment to sustain motivation and task interest in therapy. There is still a need for homebased rehabilitation ideas that will work and deal with the challenge of cost, boredom, and compliance with prescribed exercise routines that are diverse, complex, and functional. These papers offer several novel ways to promote task-engagement and complex problem solving, two elements that are thought to be key to plasticity.

Johnson, Feng, and colleagues [38] discuss a novel Robot/ computer-assisted suite of assisted devices for homebased therapy that attempts to tap into patient's need for personal and fun therapy to sustain motivation in undersupervised environments. The proposed system stresses a low-cost approach that is much needed in this field. They describe the use of distinct off-the-shelf and custom forcefeedback joystick and wheel systems that are all usable with a custom-made software called Unitherapy. Also using games as a platform for training, the next article by Colombo, Pisano, and colleagues [39] demonstrate the effectiveness of two low-cost robotic systems, the planar 2-DOF robot called MULOS and a wrist robot. The combined system focused on the shoulder and elbow and wrist pronation and supination. Along with standard and custom clinical measures, they used an intrinsic motivation scale by McAuley [40] to assess the attention and interest of their stroke subjects. Their study provides further indication of the utility of low-cost, game-based platforms and new metrics that can quantify engagement.

In the article by Mataric, Eriksson, and colleagues [41] we gain a novel perspective on how non-contact robotic systems can be of use in rehabilitation of the stroke survivor. Coining the term "socially assistive robots," they demonstrate the novel use of an autonomous mobile platform programmed with several levels of feedback and monitoring capability. They demonstrate the effectiveness of the system in monitoring limb use while providing encouragement and reminders throughout a therapy session. This study provides a humanoid-like solution to the under-supervised clinical environment with the provision of the feedback via a robot embodying human qualities.

Finally in this series, Amirabdollahian, Loureiro, and colleagues [42] discuss results from using the Gentle/s robot therapy system, which is a virtual reality and haptic enhanced training environment. They examine the results using a novel multivariate regression analysis tools. Their results support the potential of better evaluation methods capable of detecting performance changes due to robotassisted therapy systems.

\section{New control and modeling strategies for Robot-Assisted Training}

The next set of three articles describe solutions and ideas for improving the modeling and control of robot-assisted therapy systems to aide them in adapting patients' movements to natural and functional activities such as walking, drinking, and pinching. In the past other researchers have examined the use of error to improve motor adaptation for a point to point task after stroke [13]. For the lower limbs, Emken, Benitez, and Reinkensmeyer [43] describe a novel assist-as-needed training strategy for gait rehabilitation during walking. The strategy assumes that learning a novel gait pattern can be modeled based on motor learning strategy that optimizes performance error and robotic assistance to provide the most natural assistive training. For the upper limb, Matsouka, Brewer, and Klatzky [44] provide compelling experimental data demonstrating the usefulness of a novel visual distortion technique that uses error magnification to improve motor performance of a pinching task (index finger and thumb movements). Their results provide a new method to deal with compensatory movements and learn non-use that often plagues patients after stroke. These two papers support that use of error feedback and error distortion to enhance motor learning and improving walking and pinching patterns.

Finally, Wisneski and Johnson [45] suggest that there is a need for new modeling approaches to upper limb robotassisted therapies that support more ADL-related training. Specifically, they examine how best to implement trajectory planning for an Activity of Daily Living (ADL)-oriented approach to robot-assisted therapy with the goal of improving the ability of the ADL Exercise Robot (ADLER) to assist in the training and recovery of functional tasks such as drinking. They compare the classical minimum jerk model [46] for point-to-point movements with actual movements to perform a drinking task and speculate on what is needed for a more functional model. Their results suggest that new modeling strategies are needed in order to support more functional movements.

\section{Conclusion}

The special issue presented nine articles that seek to capitalize on new developments in neuro-rehabilitation after stroke to improve the effectiveness of robot-assisted stroke rehabilitation. Improvements may be achieved by providing robot training environments that incorporate into their design and control strategies important elements key to inducing motor learning and cerebral plasticity such as 
mass-practice, feedback, task-engagement, and complex problem solving. Novel design and control strategies covered in this issue provide new methods for training more natural movements, for inducing faster motor learning control of more complex movements salient to everyday activities, and for encouraging engagement and compliance in under-supervised environments such as the home and over-burdened clinics.

\section{Competing interests}

The author(s) declare that they have no competing interests.

\section{Authors' contributions}

MJJ was the primary composer of the manuscript and was responsible for the intellectual content of the manuscript and gave final approval of the version to be published.

\section{Acknowledgements}

The author acknowledge the contributions to this special issue and the support of the Editor of the Journal of Neuroscience Engineering and Rehabilitation

\section{References}

I. Heart Disease and Stroke Statistics - 2005 Update. Dallas, TX: American Heart Association; 2005.

2. Prange GB, Jannink MJA, Groothuis-Oudshoorn CGM, Hermens HJ, ljzerman MJ: Systematic review of the effect of robot-aided therapy on recovery of the hemiparetic arm after stroke. J Rehabil Res Dev 2006, 43(2): I7|- 184

3. Volpe BT, Ferraro M, Lynch D, Christos P, Krol J, Trudell C, Krebs $\mathrm{HI}$, Hogan N: Robotics and other devices in the treatment of patients recovering from stroke. Current Neurology \& Neuroscience Reports 2002, 5(6):465-70.

4. Lum P, Reinkensmeyer D, Mahoney R, Rymer WZ, Burgar C: Robotic Devices for movement therapy after stroke: Current status and challenges to clinical acceptance. Top Stroke Rehabil 2002, 8(4):40-53.

5. Fasoli SE, Krebs HI, Stein J, Frontera WR, Hogan N: Effects of robotic therapy on motor impairment and recovery in chronic stroke. Archives of Physical Medicine \& Rehabilitation 2003, 84(4):477-82.

6. Loureiro R, Amirabdollahian F, Topping M, Driessen B, Harwin W: Upper limb robot mediated stroke therapy-GENTLE/s approach. Autonomous Robots 2003, I 5(I):35-5I.

7. Burgar CG, Lum PS, Shor PC, Van der Loos HFM: Development of robots for rehabilitation therapy: the Palo Alto VA/Stanford experience. J Rehabil Res Dev 2000, 37(6):663-674.

8. Uhlenbrock D, Sarkodie-Gyan T, Reiter F, Konrad M: Development of a servo-controlled Gait Trainer for the rehabilitation of non-ambulatory patients. Biomed. Technik 1997, 42:196-202.

9. Hesse S, Uhlenbrock D, Werner C, Bardeleben AA: Mechanized Gait Trainer for restoring gait in nonambulatory subjects. Arch Phys Med Rehabil 2000, 81 : I I58-I I62.

10. [http://www.hocoma.ch/index.php?lang=en\&page=/pages/lokomat/ lokomat system en.html].

II. Hidler J, Nichols D, Pelliccio M, Brady K: Advances in the understanding and treatment of stroke impairment using robotic devices. Top Stroke Rehabil 2005, I 2:22-35.

12. Johnson MJ, Wisneski KJ, Anderson J, Nathan D, Smith R: Development of ADLER: The Activities of Daily Living Exercise Robot. In IEEE-EMBS Biomedical Robotics (BioRob 2006) Pisa, Italy; 2006:88I-886

13. Wei Y, Bajaj P, Scheidt R, Patton JL: Visual Error Augmentation for Enhancing Motor Learning and Rehabilitative Relearning. In IEEE International Conference on Rehabilitation Robotics Chicago, IL; 2005.
14. Sukal TM, Dewald JPA, Ellis MD: Use of a Novel Robotic System for Quantification of Upper Limb Work Area Following Stroke. In IEEE International Conference on Rehabilitation Robotics Chicago, IL; 2005:5032-5035.

15. Hornby TG, Campbell DD, Zemon DH, Kahn JH: Metabolic costs and muscle activity patterns during robotic- and therapistassisted treadmill walking in individuals with incomplete spinal cord injury. Phys Ther 2006, 86(I I): 1466-78.

16. Trombly C: Occupational Therapy of Physical Dysfunction. Edited by: Trombly C. Baltimore (MD): Williams \& Wilkins; 1995.

17. Will B, Galani R, Kelche C, Rosenzweig MR: Recovery from brain injury in animals: relative efficacy of environmental enrichment, physical exercise or formal training (1999-2002). Progress in Neurobioloby 2004, 72(3): 167-182.

18. Nudo RJ: Functional and structural plasticity in motor cortex: implications for stroke recovery. Physical Medicine \& Rehabilitation Clinics of North America 2003, I4(I):57-76.

19. Bach-y-Rita P: Late post-acute neurologic rehabilitation: neuroscience, engineering and clinical programs. Arch Phys Med Rehab 2003, 84: I 100-II 08.

20. Wu C, Trombly CA, Lin K, Ticke-Degnen L: Effects of object affordances on reaching performance in persons with and without cerebrovascular accident. Am J Occup Ther 1998.

21. Fisher BE, Sullivan KJ: Activity-Dependent factors affecting poststroke functional outcomes. Top Stroke Rehabil 200I, 8(3):3 I-44.

22. Bayona NA, Bitensky J, Salter K, Teasell R: The role of task-specific training in rehabilitation therapies. Topics in Stroke Rehabilitation 2005, I 2(3):58-65

23. Bayona NA, Bitensky J, Salter K, Teasell R: Plasticity and reorganization of the uninjured brain. Topics in Stroke Rehabilitation 2005, I2(3): $1-10$

24. You SH, Jang SH, Kim YH, Hallett M, Ahn SH, Kwon YH, Kim JH, Lee MY: Virtual reality-induced cortical reorganization and associated locomotor recovery in chronic stroke: an experimenter-blind randomized study. Stroke 2005, 36(7): 1625 .

25. Johnson MJ, Van der Loos HFM, Burgar CG, Shor P, Leifer LJ: Experimental results using force-feedback cueing in robot-assisted stroke therapy. IEEE Trans. on Neural Systems and Rehabilitation Engineering 2005, I3(3):335-348.

26. Bach y Rita P, Wood S, Leder R, Paredes O, Bahr D, Bach-y-Rita EW, Murillo N: Computer assisted motivating rehabilitation for institutional, home, and educational late stroke programs. Top Stroke Rehabil 2002, 8(4): I-I0.

27. Wood SR, Murillo N, Bach-y-Rita P, Leder RS, Marks JT, Page SJ: Motivating, game-based stroke rehabilitation: a brief report. Topics of Stroke Rehabilitation 2003, I (2): 134-40.

28. Karni A, Meyer G, Jezzard P, Adams MM, Turner R, Ungerleider LG: Functional MRI evidence for adult motor cortex plasticity during motor skill learning. Nature 1995, 377(6545): $155-158$.

29. Liepert J, Bauder H, Miltner WHR, Taub E, Weiller C: Treatmentinduced cortical reorganization after stroke in humans. Stroke 2002, 31:1210-1216.

30. Classen J, Liepert J, Wise S, Hallett M, Cohen LG: Rapid plasticity of human cortical movement representation induced by practice. Journal of Neurophysiology 1998, 79(2): I I I7-I I 23.

31. Calautti C, Baron J: Functional neuroimaging studies of motor recovery after stroke in adults: A review. Stroke 2003, 34:1553-I566.

32. Schaechter JD: Motor rehabilitation and brain plasticity after hemiparetic stroke. Progress in Neurobiology 2004, 73(I):6I-72.

33. Kleim JA, Hogg TM, VandenBerg PM, Cooper NR, Bruneau R, Remple $M$ : Cortical synaptogenesis and motor map reorganization occur during late, but not early, phase of motor skill learning. J Neuroscience 2004, 24(3):628-633.

34. Lünenburger L, Colombo G, Riener R: Biofeedback for Robotic Gait Rehabilitation. Journal of NeuroEngineering and Rehabilitation 2006.

35. Schmidt H, Hesse S, KrÄuger J: Gait Rehabilitation Machines based on Programmable Foot-plates. Journal of NeuroEngineering and Rehabilitation 2006.

36. Reinkensmeyer DJ, Pang CT, Nessler JA, Painter CC: Web-based telerehabilitation for the upper extremity after stroke. IEEE Trans Neural Systems Rehabilitation Engineering 2002, 10(2): 102-108. 
37. Johnson MJ, Van der Loos HFM, Burgar CG, Shor P, Leifer L: Driver's SEAT, A car steering upper limb therapy device. Robotica 2003, 2 I (I): 13-23.

38. Johnson MJ, Feng X, Johnson LM, Winters JM: Potential of a Suite of Robot/Computer-Assisted Motivating Systems for Personalized, Home-Based, Stroke Rehabilitation. Journal of NeuroEngineering and Rehabilitation 2006

39. Colombo R, Pisano F, Mazzone A, Delconte C, Micera S, Chiara Carrozza M, Dario P, Minucol G: Design Strategies to Improve Patient Motivation During Robot-Aided Rehabilitation. Journal of NeuroEngineering and Rehabilitation 2006.

40. McAuley E, Duncan T, Tammen V: Psychometric properties of the intrinsic motivation inventory in a competitive sport setting: a confirmatory factor analysis. Research Quartely for Exercise and Sport 1987, 60:48-58.

41. Mataric' MJ, Eriksson J, Feil-Seifer D, Winstein C: Socially Assistive Robotics for Post-Stroke Rehabilitation. Journal of NeuroEngineering and Rehabilitation 2006.

42. Amirabdollahian F, Loureiro RC, Gradwell E, Collin C, Harwin W, Johnson G: Multivariate Analysis of the Fugl-Meyer Outcome Measures Assessing the Effectiveness of GENTLE/S RobotMediated Stroke Therapy. Journal of NeuroEngineering and Rehabilitation 2006

43. Emken JL, Benitez R, Reinkensmeyer DJ: Human-Robot Cooperative Movement Training: Learning a Novel Sensory Motor Transformation during Walking with Robotic Assistance-asNeeded. Journal of NeuroEngineering and Rehabilitation 2006.

44. Matsuoka Y, Brewer BR, Klatzky RL: Using Visual Feedback Distortion to Alter Coordinated Pinching Patterns for Robotic Rehabilitation. Journal of NeuroEngineering and Rehabilitation 2006.

45. Wisneski KJ, Johnson M]: Quantifying Kinematics of Purposeful Movements to Real, Imagined, or Absent Functional Objects: Implications for Modelling Trajectories for RobotMediated ADL Tasks. Journal of NeuroEngineering and Rehabilitation 2006.

46. Flash T, Hogan N: The coordination of arm movements: An experimentally confirmed mathematical model. The Journal of Neuroscience 1985, 5:1688-1703.

Publish with Bio Med Central and every scientist can read your work free of charge

"BioMed Central will be the most significant development for disseminating the results of biomedical research in our lifetime. "

Sir Paul Nurse, Cancer Research UK

Your research papers will be:

- available free of charge to the entire biomedical community

- peer reviewed and published immediately upon acceptance

- cited in PubMed and archived on PubMed Central

- yours - you keep the copyright
BioMedcentral 